\title{
Fazer das tripas cérebro: A Montanha Sagrada, de Alejandro Jodorowsky e o mito da superioridade intelectual europeia como forma de dominação e exploração colonial
}

DOI: https://doi.org/10.35168/2176-896X.UTP.Tuiuti.2020.Vol6.N61.pp4-27

(c) $($ i) (:) 


\section{Fazer das tripas cérebro: A Montanha Sagrada, de Alejandro Jodorowsky e o mito da superioridade intelectual europeia como forma de dominação e exploração colonial}

\section{Resumo}

O objetivo deste artigo é abordar três cenas do filme $A$ montanha sagrada, de Alejandro Jodorowsky, à luz das discussões desenvolvidas pelas teorias decoloniais. Utilizamos como autores base a pesquisadora brasileira Maíra Zenun de Oliveira e o teórico estadunidense Robert Stam para pensar as relações entre arte, cinema e decolonialidade. A metodologia utilizada para pensar as temáticas propostas se estabeleceu através da identificação de pontos de contato entre os autores, pensando de que maneira o pensamento de ambos converge para uma possível leitura de imagens presentes no filme. Nesse sentido, foi construída uma leitura do fenômeno cinematográfico enquanto um elemento de resistência aos modos de funcionamento das lógicas colonizadoras, tendo em vista a intensificação dos debates em torno das questões identitárias na contemporaneidade.

Palavras-chave: Cinema. Decolonialidade. Jodorowsky. 


\section{Hacer de tripas cerebro: La Montaña Sagrada, de Alejandro Jodorowsky y el mito de la superioridad intelectual europea como forma de dominación y exploración colonial}

\section{Resumen}

El objetivo de este artículo es acercar tres escenas de la película La montaña sagrada, de Alejandro Jodorowsky, a la luz de las discusiones desarrolladas por las teorías decoloniales. Usamos como autores base la investigadora brasileña Maíra Zenun de Oliveira y el teórico estadunidense Robert Stam para pensar las relaciones entre el arte, el cine y la decolonialidad. La metodología utilizada para pensar los temas acercados ocurrió mediante la identificación de puntos de convergencia entre los autores, buscando pensar la manera como el pensamiento de ambos converge para una posible lectura de las imágenes de la película. En ese sentido, fue considerado el cine como un elemento de resistencia a los modos de operación de la colonialidad, considerando la intensificación de los debates acerca de las cuestiones de la identidad en la contemporaneidad.

Palabras clave: Cine. Decolonialidad. Jodorowsky. 


\section{Fazer das tripas cérebro: A Montanha Sagrada, de Alejandro Jodorowsky e o mito da superioridade intelectual europeia como forma de dominação e exploração colonial}

\section{Introdução}

Partindo da temática cinema e (des)colonização, surge o questionamento de como o fenômeno cinematográfico se apresenta como uma engrenagem nos sistemas colonizadores. Da mesma forma que podemos considerá-lo como um mecanismo de elaboração e implementação de uma lógica de dominação colonizadora, no campo subjetivo e sensorial, é evidente que contrariamente a isso ele também pode ser utilizado como ferramenta de discussão e rompimento da colonialidade. Experimentamos na contemporaneidade, no Brasil e na maior parte dos países do mundo, um movimento de intensificação dos debates em torno das questões identitárias. Nessas discussões se apresenta uma tensão entre um eixo normativo e o que é considerada a margem desse eixo. Juntamente com as discussões apresentadas pelas teorias feministas, pelas teorias queer, pelo movimento negro, se insere a temática das identidades colonizadas territorial e politicamente. Nesse sentido, é de extrema importância que, enquanto populações sulamericanas (diversas em suas especificidades), debatamos os impactos dos processos coloniais que sofremos (no passado e no presente) em nossas identidades individuais e coletivas.

Por compreendermos o cinema como um dispositivo afetivo, acreditamos que ele se insere nesse debate. Portanto, nesse artigo partiremos da discussão proposta por Maíra Zenun de Oliveira acerca das relações entre cinema e construção de um imaginário simbólico, pensando como tais relações funcionam como possibilidades de questionamentos de lógicas coloniais. A partir das ideias apresentadas por Oliveira, relacionaremos a discussão com o pensamento de Robert Stam sobre o fenômeno cinematográfico e o imperialismo europeu. Buscaremos evidenciar de que 


\section{Fazer das tripas cérebro: A Montanha Sagrada, de Alejandro Jodorowsky e o mito da superioridade intelectual europeia como forma de dominação e exploração colonial}

forma Oliveira constrói uma noção de cinema enquanto dispositivo de desestruturar os vetores de colonização do pensamento e de um imaginário simbólico.

Em um segundo momento do texto, abordaremos, a partir do pensamento de Stam, as reverberações do mito da superioridade intelectual europeia no campo da historiografia da arte, buscando evidenciar como o autor desmistifica e questiona algumas verdades criadas a partir da autorrepresentação européia no âmbito das teorias e histórias das artes. Por fim, faremos uma análise de três cenas do filme A Montanha Sagrada (1973), dirigido por Alejandro Jodorowsky, pensando como o filme dialoga com as temáticas desenvolvidas pelos autores.

\section{0 cinema e a reinvenção de imaginários simbólicos}

Maíra Zenun de Oliveira, em seu artigo Sobre a colonialidade do pensamento em imagens e a reinvenção da negritude no FESPACO: maior festival de cinema africano, busca discutir o papel simbólico e político do cinema nas lutas de rompimento com as lógicas euro-ocidentais racistas de dominação colonial (em seus aspectos geográficos, econômicos, políticos, culturais, de representação e de pensamento).

Robert Stam relaciona o surgimento e disseminação do fenômeno cinematográfico com o imperialismo e colonialismo protagonizados pela continente europeu:

Se os primórdios do romance europeu (Robinson Crusoé) coincidiram com o momento inicial da conquista colonial e da escravidão transatlântica, a origem do cinema coincidiu com o paroxismo imperial da dominação européia. Os países que mais produziram filmes durante a era do cinema mudo - Inglaterra, França, Estados Unidos e Alemanha - também, 


\title{
Fazer das tripas cérebro: A Montanha Sagrada, de Alejandro Jodorowsky e o mito da superioridade intelectual europeia como forma de dominação e exploração colonial
}

\begin{abstract}
"por acaso" figuraram entre os países líderes do imperialismo, cujo declarado interesse era enaltecer o empreendimento colonial. O cinema combinou narrativa e espetáculo para contar a história do colonialismo a partir da figura do colonizador. De todas as celebradas "coincidências" - dos primórdios do cinema com a psicanálise, o surgimento do nacionalismo, a emergência do consumismo - é a coincidência com o imperialismo que é a menos estudada. (STAM, 2008, p. 35)
\end{abstract}

Oliveira (2016) considera o cinema como elemento fundamental para a libertação do pensamento para com as lógicas coloniais e exploratórias e desenvolve tal argumento a partir da capacidade cinematográfica e midiática de reconstrução das identidades de sociedades exploradas e devoradas pela dominação europeia. As imagens cinematográficas, ao mesmo tempo em que podem servir como forma de dominação (notemos também o fato de que o cinema foi um elemento fundamental para a propagação de ideais nazi-fascistas no século XX) também podem funcionar como uma força de rompimento com a lógica do opressor, na medida em que consistem em um dispositivo afetivo capaz de construir memórias, representações e imaginários simbólicos.

Oliveira, neste artigo, aborda especificamente as temáticas em torno da negritude e a decolonialidade, porém é possível elencar algumas considerações construídas pela autora e ampliá-las para outros campos de discussão sobre as explorações coloniais, como, por exemplo, o extermínio de sociedades originárias ameríndias, como parte de um projeto europeu de dominação exploratória.

Tal projeto, como colocado pela autora, consistiu em um exercício de autorrepresentação da branquitude europeia forjada a partir do mito da Europa como o ápice da civilização, supostamente 


\section{Fazer das tripas cérebro: A Montanha Sagrada, de Alejandro Jodorowsky e o mito da superioridade intelectual europeia como forma de dominação e exploração colonial}

avançada e moderna em relação à ciência, à filosofia e à construção epistemológica. Como consequência, tal projeto de autorrepresentação europeia opera sob falsas perspectivas que inferiorizam e depreciam todas aquelas culturas que lhes são outras. Todas as culturas, periféricas em relação ao eixo dos modos de produção capitalista, que não operam a partir das lógicas epistemológicas europeias. Esse conhecimento, narrado como universal, possibilitou uma série de atrocidades derivadas dos sistemas coloniais e é problematizado por pensadores que reconhecem as profundas e débeis falhas desta lógica eurocêntrica e apontam a suposta racionalidade europeia como produtora de catástrofes.

Nesse sentido, as teorias decoloniais surgem como forma de contestação e proposição de rompimento com as lógicas euro-ocidentais de dominação dos não-europeus. Um dos pressupostos mais centrais para a construção dos pensamentos decoloniais é o de que não há conhecimento universal. Ou seja, todos os aspectos culturais, científicos e epistemológicos produzidos pela Europa, em sua feroz exploração, são específicos, arbitrários, profundamente limitados e passíveis de problematizações.

À luz dessas noções proponho relacionar três cenas (que no âmbito deste artigo intitulamos como: Institucionalização do massacre; A conquista do México e A fabricação dos Cristos) do filme A montanha sagrada (1973), de Alejandro Jodorowsky, com aspectos dos pensamentos decoloniais e com discussões feitas por Robert Stam na introdução de seu livro $A$ literatura através do cinema: realismo, magia e a arte da adaptação. 


\section{Fazer das tripas cérebro: A Montanha Sagrada, de Alejandro Jodorowsky e o mito da superioridade intelectual europeia como forma de dominação e exploração colonial}

\section{Racionalidade e catástrofe}

Para além da política e da economia, a arte é também um campo que contém e revela algumas das ficções criadas pela lógica eurocêntrica de dominação colonial. Isso revela que a construção de uma historiografia e teoria da arte também é um possível vetor de colonização, na medida em que se forjam verdades que autorrepresentam os colonizadores como detentores e criadores de práticas artísticas que não lhes são próprias ou cujas gêneses podem ser identificadas em outros povos. Uma análise mais meticulosa e crítica das verdades criadas no universo das artes europeias, colocadas como pontos inquestionáveis nos cânones das teorias das artes, podem atestar que muitos de seus aspectos, desde a antiguidade clássica, são apropriações, ressignificações e desdobramentos de práticas artísticas de outras culturas. Culturas essas que, em muitos e quase todos os casos, foram alvo dos sistemas de colonização política, econômica, geográfica, simbólica e artística.

Um destes aspectos, apontado por Robert Stam, a partir das críticas de Arthur Heiserman e Margaret Anne Doody, é a ideia do romance enquanto fenômeno criado no iluminismo europeu, que desconsidera o fato de que ele "tem uma história contínua de cerca de dois mil anos" (STAM, 2008, p.25). O autor exemplifica este ponto pensando em como a crítica literária européia rejeita o romance de cavalaria, tido como uma forma arcaica e mágica que cria rompimentos na tese do romance como o signo da modernidade europeia:

Uma grande variedade de críticos compartilha uma abordagem teleológica, quase hegeliana, que sublinha a preponderância "progressista" dos vestígios do passado. Dentro dessa narrativa de extermínio, formas "arcaicas" e "medievais" como a épica 


\title{
Fazer das tripas cérebro: A Montanha Sagrada, de Alejandro Jodorowsky e o mito da superioridade intelectual europeia como forma de dominação e exploração colonial
}

\begin{abstract}
e o romance de cavalaria inevitavelmente cedem espaço a formas modernas como o romance, do mesmo modo que a aristocracia palaciana cede espaço a classe média, e a mágica "oriental” dá lugar a ciência "ocidental (STAM, 2008, p. 26)
\end{abstract}

Sobre este ponto, é interessante retomarmos o artigo de Oliveira (2016), em que ela demonstra que a própria noção de modernidade é inseparável da de colonialidade. Ou seja, no caso do romance, podemos afirmar que foi uma forma literária absorvida pelos europeus de culturas árabes, orientais e norteafricanas, a qual foi inserida em uma narrativa duplamente falsa (STAM, 2008). Não apenas o romance não foi um produto da modernidade europeia, como o próprio mito da modernidade europeia foi forjado a partir de uma lógica de dominação exploratória, como testifica a apropriação de formas prosaicas que culminaram no romance. Assim também a Bíblia e as mitologias cristãs, de forma geral, foram cunhadas a partir de influências de diversas culturas e posteriormente utilizadas como uma arma de dominação e extermínio de outras culturas, inclusive daquelas que lançaram influências sobre a própria Bíblia e as instituições ditas cristãs.

Existe uma série de outros mitos gerados pelo mito original da superioridade intelectual, racional e científica da Europa, que dentro de sua falsa narrativa, se opõe ao atraso intelectual de culturas que não operam segundo lógicas narrativas letradas e nas quais o pensamento mágico exerce uma função especialmente importante. Nesse sentido, outro mito no qual Stam se debruça para questionar a hegemonia da lógica europeia é a ideia de realismo como símbolo do pensamento racional iluminista: 


\title{
Fazer das tripas cérebro: A Montanha Sagrada, de Alejandro Jodorowsky e o mito da superioridade intelectual europeia como forma de dominação e exploração colonial
}

\begin{abstract}
Uma visão linear, "progressista" de tais questões considera que a humanidade tenha "ultrapassado" essas formas arcaicas e irracionais; o mundo move-se para frente, inexoravelmente, em um curso global e unidirecional. A magia e o romance desvalorizamse como vestígios anacrônicos ou velhos modos de consciência a serem "superados" por formas mais evoluídas e racionais da Modernidade Iluminista. A fantasia e a magia, nessa perspectiva, são vestígios de um passado que é melhor esquecer. Mas essas formas arcaicas nunca são completamente enterradas. Pelo contrário, seus espectros assombram, ou melhor, animam toda história da ficção moderna [...] (STAM, 2008, p. 27)
\end{abstract}

Percebemos o impulso realista permeando a tradição artística e filosófica européia desde a antiguidade clássica, da qual essa deriva ${ }^{1}$. Aristóteles, na Poética, considerada um dos principais cânones da historiografia da arte européia, propõe a imagem metafórica do belo animal (ARISTÓTELES, 2004, p. 51) para construir as proposições acerca da arte, mais especificamente aqui, da tragédia clássica, na qual o conceito de mimesis tem uma importância fundamental. Além disso, notemos o fato de que a tragédia, quando comparada à comédia, foi considerada por tal tradição como um gênero superior, pois, diferentemente desta, a tragédia aborda a grandeza e a elevação moral de figuras ilustres. (CAMPOS, 2012, p. 35). Aristóteles então propõe uma leitura da tragédia como uma arte que funciona segundo critérios específicos de criação, que deveria ser construído a partir de uma lógica coerente resultando em um belo animal. Portanto as relações entre mimesis, realismo e racionalidade atravessam profundamente a tradição da arte européia,

1 Sendo essencial citar aqui, tendo em conta a temática que abordamos neste trabalho, o fato de que as civilizações greco-romanas sofreram importantes e profundas influências de outras 


\section{Fazer das tripas cérebro: A Montanha Sagrada, de Alejandro Jodorowsky e o mito da superioridade intelectual europeia como forma de dominação e exploração colonial}

bem como de suas críticas, teorias e historiografias. É dessa ilusão de superioridade intelectual que categorias como, por exemplo, o Grotesco e o Surrealismo vão debochar e questionar, mostrando que se olharmos para dentro dele, talvez o animal não nos pareça assim tão belo.

Partindo da relação que se construiu entre o realismo e a suposta superioridade intelectual europeia, Stam lê o modernismo como um fenômeno de forças extremamente particulares a um contexto europeu, provinciano em duas dimensões. A primeira delas é a Europa - e suas epistemologias - como província (que se forjou de império) em relação ao globo, pois “em imensas regiões do mundo, e por longos períodos de história da arte, houve pouca adesão ou mesmo interesse pelo realismo" (STAM, 2008, p. 27). A segunda é o provincianismo do realismo dentro mesmo do continente europeu:

Em Rabelais e seu mundo, Bakhtin fala do "carnavalesco" como uma tradição contrahegemônica cuja história vai dos festivais gregos dionisíacos e da saturnália romana ao realismo grotesco do "carnavalesco medieval", passando por Shakespeare e Cervantes, chegando finalmente a Jarry e ao Surrealismo. Conforme a teorização de Bakhtin, o carnaval abraça uma estética anticlássica que rejeita a unidade e a harmonia formal para favorecer o assimétrico, o heterogêneo, o oxímoro, o miscigenado. (STAM, 2008, p. 28)

O autor também aponta como a questão do realismo opera vetores de força nas teorias cinematográficas. O bipartidarismo no contexto da teoria clássica do cinema, nos termos de Suppia (2015), funciona como oposição teórica entre o realismo e o formalismo na busca pelo essencialismo cinematográfico. Stam aponta como a nomenclatura de alguns movimentos estéticos 


\section{Fazer das tripas cérebro: A Montanha Sagrada, de Alejandro Jodorowsky e o mito da superioridade intelectual europeia como forma de dominação e exploração colonial}

e políticos do cinema propunham alguma problematização da noção de realismo e seus parâmetros de verossimilhança (surrealismo, realismo poético, neorrealismo, realismo subjetivo, surrealismo ou realismo do sul). Podemos observar então que, apesar do realismo ter sido muito defendido enquanto dimensão para um ideal de cinema, muitos cineastas, críticos e teóricos propõem rompimentos com a lógica realista. Porém o que mais interessa na discussão proposta por Stam no escopo deste trabalho é a especificidade de contexto do realismo, não apenas no cinema, mas também para outras linguagens. Ademais, podemos ler a lógica do realismo, enquanto proposição estética, como um reflexo de uma lógica de funcionamento do pensamento de tradição europeia, ao qual comumente foram associadas características como racional, científico, linear e apolíneo; isto é: um pensamento que se supõe ser bem construído. Porém só é possível caracterizar as lógicas epistemológicas euro-ocidentais como bem construídas a partir de suas próprias perspectivas, sendo historicamente condicionado até mesmo em seus próprios contextos de produção (STAM, 2008, p. 30). O "belo animal" de Aristóteles é completamente estranho fora de seu habitat natural. Além de correr o eterno risco de ser devorado por outros, como certamente poderia atestar o bispo Sardinha, tema que impulsiona produções artísticas até a atualidade (Fig. 1). 


\section{Fazer das tripas cérebro: A Montanha Sagrada, de Alejandro Jodorowsky e o mito da superioridade intelectual europeia como forma de dominação e exploração colonial}

Figura 1 - Intervenção digital a partir de gravura portuguesa sobre o canibalismo tupinambá, baseada nos escritos de Hans Staden. Coletivo Opavivará (RJ). 2012.

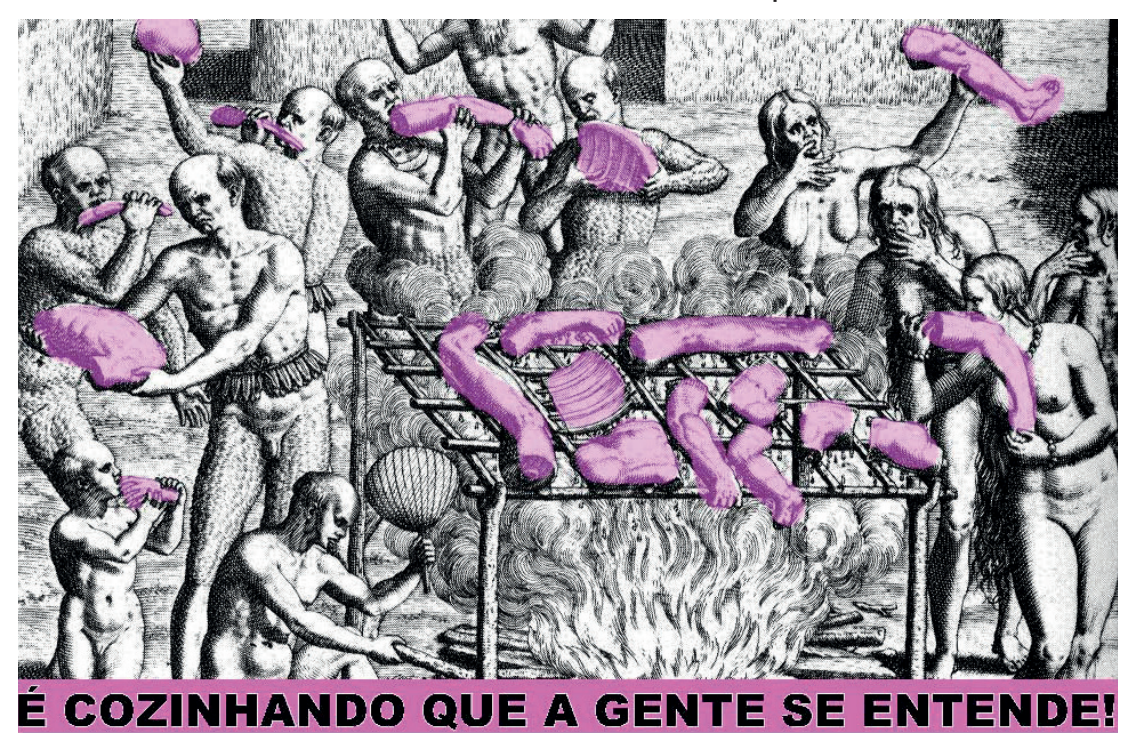

Fonte: http://g1.globo.com/platb/files//2097/2012/05/cartaz11.jpg

A imagem acima criada pelo Coletivo Opavivará propõe uma discussão dessa temática utilizando a ironia como potência questionadora. O coletivo artístico, criado em 2005 no Rio de Janeiro, propõe ações performativas relacionadas à ocupação do espaço urbano e às práticas coletivas de indivíduos e grupos nele inseridos. É comum, no trabalho do grupo, a utilização do 


\section{Fazer das tripas cérebro: A Montanha Sagrada, de Alejandro Jodorowsky e o mito da superioridade intelectual europeia como forma de dominação e exploração colonial}

humor para criar inversões que evidenciam e friccionam críticas ao modo de operação social. A imagem é uma intervenção que colore uma icônica ilustração, uma das primeiras representações do recém invadido continente americano, de Theodore de Bry, a partir de relatos de Hans Staden. A intervenção subverte um famoso ditado popular que diz "É conversando que a gente se entende". Ao substituir o verbo conversando pelo verbo cozinhando, adicionando a intervenção imagética, o coletivo aproxima a prática da antropofagia de povos ameríndios originários do termo conversa. Como conversar denota uma troca de perspectivas, a imagem aciona ironicamente a temática da colonização, é construído um sentido entre a aproximação do simples e cotidiano ato de conversar às práticas antropofágicas e outras temáticas geradas pelas práticas de invasão colonial.

A partir da ponte entre o realismo estético e as lógicas epistemológicas dominantes no eixo capitalista de tradição européia, ambas compreendidas como vetores de colonização em diversas dimensões, podemos apontar como cinemas decoloniais as produções cinematográficas que se recusam a moldar-se pela subserviência aos parâmetros daqueles.

A Montanha Sagrada (1973), dirigido por Alejandro Jodorowsky é um destes exemplos de um cinema disruptivo que se nega a sujeitar-se aos moldes hegemonicamente convencionados de narrativa e linguagem cinematográfica, pois subverte totalmente os parâmetros de organização espaço-temporal, de continuidade, de coerência linear. E o faz não apenas diegeticamente, ao imaginar (transformar em imagens) temáticas relacionadas ao colonialismo, mas também a partir da materialidade do próprio filme que se evidencia como realidade criada e ficcional. 


\section{Fazer das tripas cérebro: A Montanha Sagrada, de Alejandro Jodorowsky e o mito da superioridade intelectual europeia como forma de dominação e exploração colonial}

\section{Sob a ameaça da cruz: a institucionalização do massacre}

No longa metragem A Montanha Sagrada, aos 6 minutos e 18 segundos, o filme inicia uma sequência que evidencia algumas temáticas que tocam na questão da colonialidade. $\mathrm{O}$ filme apresenta uma série de símbolos que fazem referência às culturas latino americanas que vão desde a corporeidade de atores e figuração até figurinos e elementos visuais. Podemos perceber esta relação no plano que mostra um amontoado de jovens nus, mortos e ensanguentados em um caminhão. O fenótipo dos atores apresentados neste plano é muito semelhante ao fenótipo de grupos originários ameríndios, como a tonalidade de pele e cabelos e traços faciais. Poderíamos ler este plano como uma referência ao genocídio indígena promovido principalmente por Portugal e Espanha na ocasião da invasão do então denominado continente americano pelos europeus ou até mesmo aos regimes ditatoriais latino americanos nas décadas de 1960 e 1970. Dado o contexto da Guerra Fria e a disposição geopolítica de um conflito ideológico entre Estados Unidos e a União Soviética, muito regimes autoritários se estabeleceram no Chile, Brasil, Argentina, Bolívia e Uruguai a partir de golpes de estado financiados pelos Estados Unidos como parte de seu projeto de controle da expansão comunista após a Revolução Cubana no final da década de 1950.

O caminhão passa enquanto mulheres na calçada ao fundo passam tecidos manchados de sangue e os dois companheiros caminham alegres e brincantes sob o efeito do fumo de uma erva aparentemente psicoativa. No plano seguinte, vemos cinco soldados usando máscaras de gás apontarem fuzis "em nossa direção", como se as armas estivessem sendo empunhadas para o espectador. Este plano é muito interessante, no sentido simbólico, pois expõe uma violência política 


\section{Fazer das tripas cérebro: A Montanha Sagrada, de Alejandro Jodorowsky e o mito da superioridade intelectual europeia como forma de dominação e exploração colonial}

interna que dialoga com os regimes autoritários em questão. As ditaduras funcionam a partir do controle militar que se volta para os próprios cidadãos de um país. Um exército cuja função seria proteger os cidadãos de ameaças externas, em caso de guerras, ataques ou atentados se volta para o próprio país, aniquilando aqueles que deveriam ser protegidos por este exército de uma ameaça externa.

Quando um regime ditatorial é implantado em um Estado, fazendo com que suas armas se voltem para seus próprios cidadãos, este Estado torna-se um corpo que se auto aniquila, rumo a uma progressiva destruição. Quando o espectador vê as armas apontadas em sua direção, o filme transmite a sensação desta espécie de autofagocitose bélica dos regimes ditatoriais. O plano seguinte mostra jovens amarrados e com bocas seladas com fitas pretas, denotando a censura da liberdade de expressão. Do ponto no qual os tiros os atingem jorra um sangue preto, uma possível referência ao petróleo, elemento em torno do qual se desenham inúmeros conflitos geopolíticos.

Aos 6 minutos e 38 segundos, inicia-se um plano em que vemos um desfile militar em frente a uma igreja católica com soldados carregando cães mortos presos em cruzes. A partir da aproximação do símbolo da cruz com a morte, é possível identificar uma série de discursos que abordam a questão da colonialidade, uma vez que o elemento religioso é um dos principais agentes nos processos de colonização, dominação, controle e extermínio bélico. Outras execuções são retratadas nesta cena com turistas entusiasmados fotografando pessoas mortas e um estupro. Podemos relacionar o fascínio por registrar a barbárie com a mídia e sua função de naturalização dos processos colonizadores e do horror. 


\section{Fazer das tripas cérebro: A Montanha Sagrada, de Alejandro Jodorowsky e o mito da superioridade intelectual europeia como forma de dominação e exploração colonial}

Figura 2 - Plano do filme A Montanha Sagrada. 6min. 38s. Alejandro Jodorowsky, 1973.

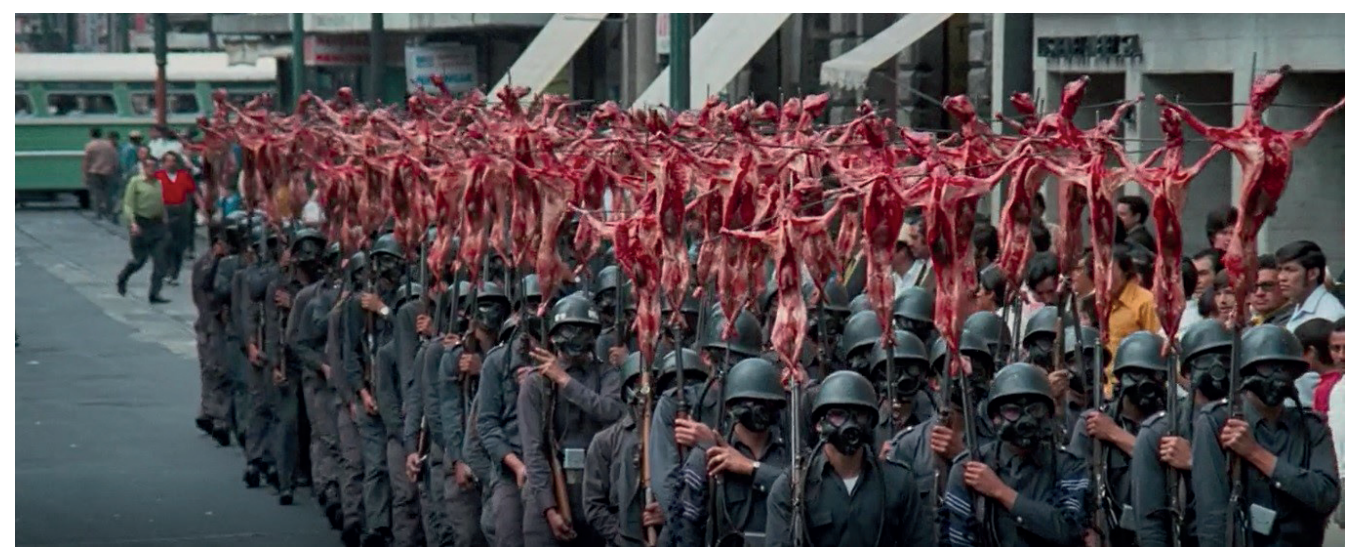

Fonte: Filme A Montanha Sagrada

\section{A conquista do México}

A cena seguinte, uma releitura de um texto dramatúrgico de Antonin Artaud intitulado $A$ conquista do México, apresenta um plano em que vemos uma placa escrita Gran Circo de Sapos y Camaleones e abaixo outra com Hoy: La conquista de Mexico. O circo apresenta uma estrutura com uma maquete com pirâmides de uma cidade de uma civilização pré-colombiana. O Ladrão, carregando o Anão em suas costas, se aproxima de dois homens que confeccionam a faixa com o título do espetáculo circense que será encenado. Outros homens se aproximam, um deles usando um chapéu 


\section{Fazer das tripas cérebro: A Montanha Sagrada, de Alejandro Jodorowsky e o mito da superioridade intelectual europeia como forma de dominação e exploração colonial}

com a suástica nazista, e o grupo comunica alguma informação incompreensível, como uma espécie de segredo. O homem com o chapéu da suástica nazista lhe entrega uma nota de dinheiro. Então eles apresentam o espetáculo que está prestes a iniciar.

Figura 3 - Plano do filme A Montanha Sagrada. 11 min. 28s. Alejandro Jodorowsky, 1973.

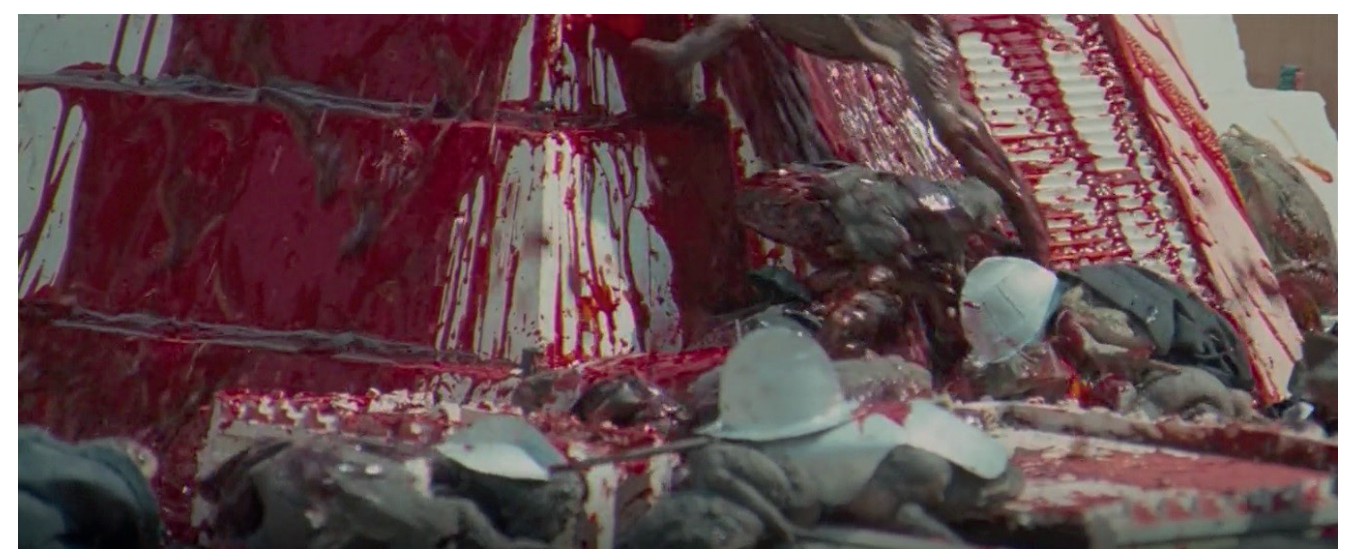

Fonte: Filme A Montanha Sagrada

O plano fílmico mostra as pirâmides habitadas por camaleões vestidos com trajes característicos incas sob a trilha sonora de uma flauta. A trilha muda para uma marcha militar cantando em repetição "eins, zwei, drei, vier, fünf" (um, dois, três, quatro, cinco, em língua alemã) quando os 


\section{Fazer das tripas cérebro: A Montanha Sagrada, de Alejandro Jodorowsky e o mito da superioridade intelectual europeia como forma de dominação e exploração colonial}

circenses chegam manipulando caravelas com cruzes de malta em suas velas. Eles colocam sapos vestidos com figurinos de invasores europeus. Os sapos se amontoam e comem os camaleões e, após a queda torrencial de sangue por uma das pirâmides, toda a maquete e os animais explodem pelos ares. A cena termina com o cenário de destruição e o público aplaudindo.

\section{A fabricação dos Cristos}

Os turistas que assistiam aos camaleões sendo digladiados pelos sapos, encontram sob uma placa de "Cristos a venda", uma pequena tenda onde homens gordos vestidos de soldados romanos vendem estátuas de Jesus Cristo, enquanto uma freira crossdresser $^{2}$ retira a pele de um boi morto na calçada e outros soldados jogam dados e amolam facas. $\mathrm{O}$ ato da freira de cortar um animal abre espaço para pensarmos as relações entre o Cristianismo e colonialismo. Não apenas no sentido de que a Igreja Católica foi uma das instituições que mais contribuíram para as barbáries imperialistas europeias e a consequente destruição de sociedades ameríndias e africanas, mas também no intrínseco caráter imperialista do Catolicismo.

20 termo designa uma prática de vestuário que subverte o binarismo de gênero. Ou seja, consiste na utilização de vestimentas que invertem as convenções de gênero. 


\section{Fazer das tripas cérebro: A Montanha Sagrada, de Alejandro Jodorowsky e o mito da superioridade intelectual europeia como forma de dominação e exploração colonial}

Figura 4 - Plano do filme A Montanha Sagrada. 12min. 13s. Alejandro Jodorowsky, 1973.

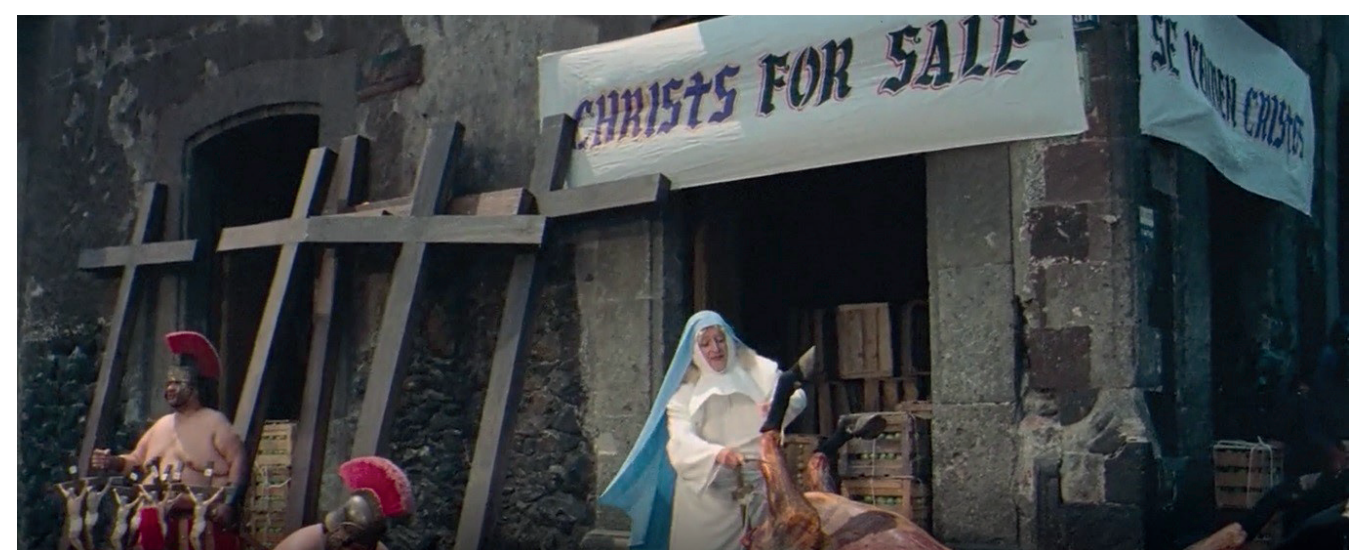

Fonte: Filme A Montanha Sagrada

Para além de ser, em si, um vetor de colonização, o Catolicismo e outros cristianismos possibilitam o funcionamento de outros vetores de colonização, de ordem econômica, política, cultural e de pensamento. A aproximação da freira com a figura de um açougueiro constrói, no filme, um discurso crítico em relação a uma religiosidade destrutiva e mortal que se alimenta ideológica e materialmente de corpos catequizados ou aniquilados em nome de Deus. Outro discurso irônico construído pelo plano é entre a ideia de gula e avareza, dois dos sete pecados capitais, aproximados aos signos religiosos. Ao representar a freira e os soldados vendendo imagens de Jesus Cristo, 


\section{Fazer das tripas cérebro: A Montanha Sagrada, de Alejandro Jodorowsky e o mito da superioridade intelectual europeia como forma de dominação e exploração colonial}

Jodorowsky expõe outra crítica ao catolicismo: a igreja como um corpo que enriquece e engorda por meio da exploração dos recursos de territórios colonizados e da venda de indulgências.

Os turistas se aproximam e um deles paga a freira para experimentar carregar uma cruz. Ao ver o Ladrão que se aproxima, ela expulsa o turista e o convoca a carregar a cruz com o auxílio do Anão. O fato de o Anão ajudá-lo a carregar a cruz não é um detalhe desimportante, uma vez que este personagem está relacionado às ilusões do ego do personagem, como o filme aponta em um momento posterior. Os soldados glutões convidam o Ladrão a beber com eles e o embebedam até que ele fique inconsciente. Então o levam desmaiado até um armazém de tubérculos e utilizam seu corpo como molde de replicação de diversas imagens de Cristo, uma vez que sua aparência é muito semelhante da imagem forjada de Jesus, pela Igreja Católica, como um homem caucasiano com traços finos e longos cabelos lisos. A representação de Jesus como um homem branco também é parte de um projeto católico de afastar a imagem crística da negritude, criando uma imagem que não condiz com o fenótipo de um homem nascido na Palestina. 


\section{Fazer das tripas cérebro: A Montanha Sagrada, de Alejandro Jodorowsky e o mito da superioridade intelectual europeia como forma de dominação e exploração colonial}

Figura 5 - Plano do filme A Montanha Sagrada. 16min. 33s. Alejandro Jodorowsky, 1973.

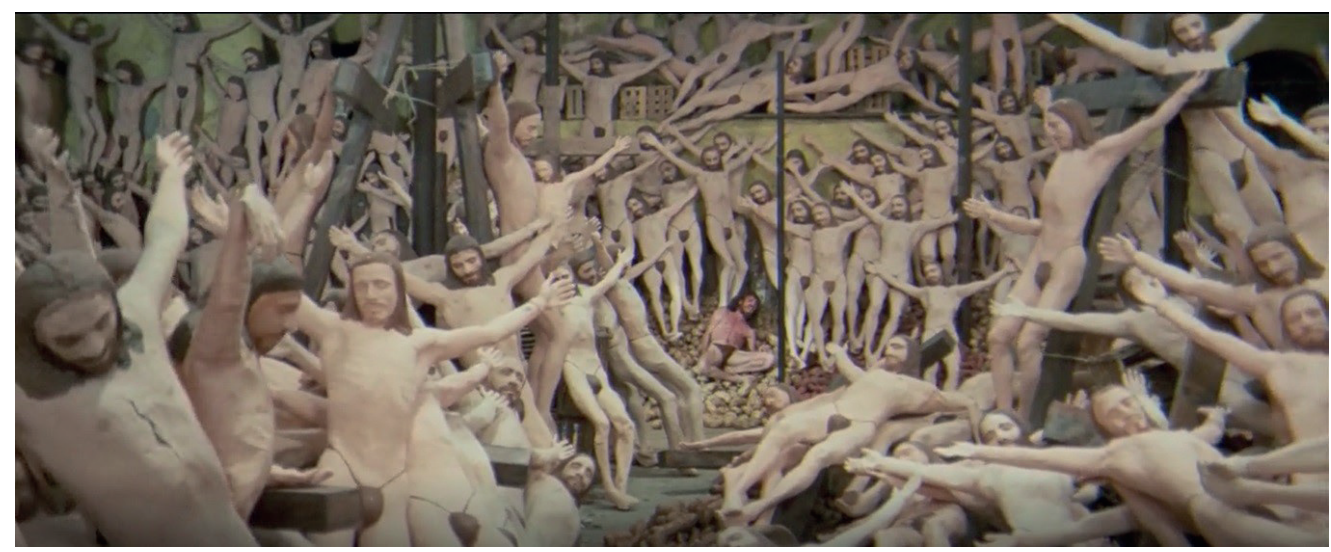

Fonte: Filme A Montanha Sagrada

Após a fabricação das réplicas, eles o atiram sobre um monte de batatas e vão dormir. Ao acordar, o Ladrão se percebe rodeado de réplicas de si mesmo como Cristo e, em um ato de fúria, as destrói e açoita os soldados e o homem vestido de freira. Uma única imagem não é destruída, a que ele carrega consigo por um tempo e que posteriormente come em um gesto antropofágico. Comer o Cristo ressignifica a simbologia da Santa Ceia, ao passo que rompe com a sacralidade do signo em um ato descolonizador que transgride a lógica religiosa imposta. 


\section{Fazer das tripas cérebro: A Montanha Sagrada, de Alejandro Jodorowsky e o mito da superioridade intelectual europeia como forma de dominação e exploração colonial}

\section{Considerações finais}

Ao lermos, em diálogo, Oliveira e Stam, concluímos que a arte e, mais especificamente, o cinema é um elemento de notável importância para a manutenção de um campo simbólico, subjetivo e afetivo. Sua importância para o campo das discussões decoloniais se apresenta por sua capacidade de recriação das representações de coletividades situadas à margem de um eixo político, econômico e identitário.

Concluímos também a importância de questionarmos as verdades canônicas acerca das teorias da arte produzidas pela autorepresentação europeia. Inserindo o filme A montanha sagrada nas discussões em torno das temáticas decoloniais, percebemos que a obra nos apresenta um espectro de símbolos, colocando-os em choque, gerando ironias que desestabilizam a narrativa da dominação colonial.

\section{Referências}

ARISTÓTELES. Poética, trad. Ana Maria Valente, Lisboa: Fundação Calouste Gulbenkian, 2004.

CAMPOS, J. N. de. Ação, destino e deliberação na tragédia grega e na Ética aristotélica.

Dissertação (Mestrado em Filosofia). 81 f. Programa de Pós-Graduação em Filosofia, Universidade Federal de Goiás, Goiânia, 2012. 


\section{Fazer das tripas cérebro: A Montanha Sagrada, de Alejandro Jodorowsky e o mito da superioridade intelectual europeia como forma de dominação e exploração colonial}

OLIVEIRA, M. Z. de. Sobre a colonialidade do pensamento em imagens e a reinvenção da negritude no FESPAÇO: maior festival de cinema africano. Rebeca - Revista Brasileira de Estudos de Cinema e Audiovisual, vol. 5, n.2, Jul-Dez. 2016.

STAM, R. A literatura através do cinema: realismo, magia e a arte da adaptação. Belo Horizonte: UFMG, 2008.

SUPPIA, A. Revendo bipartidarismos no contexto da teoria clássica do cinema: formalismo e realismo, identificação e essencialismo. Revista Matrizes. São Paulo, Universidade Estadual de Campinas. 2015.

THE HOLY MOUNTAIN. Direção de Alejandro Jodorowsky. Produção de Allen Klein. Roteiro: Alejandro Jodorowsky. Cannes: Abkco Films, 1973. (114 min.), som., cor.

Submetido em 15 de outubro de 2020

Aceito em 17 de novembro de 2020

Publicado em 18 de dezembro de 2020 